\title{
EFEITO DO SILÍCIO NA PREFERÊNCIA PARA OVIPOSIÇÃo DE Bemisia tabaci BIÓTIPO B (GENN.) (HEMIPTERA: ALEYRODIDAE) EM PLANTAS DE FEIJÃO (Phaseolus vulgaris L.)
}

\author{
Effect of silicon on the oviposition preference of Bemisia tabaci Biotype B (GENN.) \\ (Hemiptera: Aleyrodidae) on bean (Phaseolus vulgaris L.) plants
}

\author{
Marília Lara Peixoto ${ }^{1}$, Jair Campos Moraes², Alex Antônio Silva², Franscinely Aparecida Assis ${ }^{2}$
}

\begin{abstract}
RESUMO
O biótipo B de Bemisia tabaci destaca-se entre as pragas principais do feijoeiro. Neste trabalho, objetivou-se avaliar a indução de resistência à mosca-branca pela aplicação de silício em feijoeiro. Foram testados 4 tratamentos, em esquema fatorial 2 (cultivares Carioca e Valente) x 2 (com e sem aplicação de silício) e 6 repetições. Dez dias após a emergência das plântulas, foram aplicados 500 $\mathrm{ml}$ de solução de ácido silícico a $1 \%$ no solo, na dosagem equivalente a 2 t $\mathrm{SiO}_{2} / \mathrm{ha}$. Dez dias após a aplicação do silício, as plantas foram infestadas com adultos não sexados de mosca-branca em sala climatizada, sendo 100 moscas-brancas/vaso. Para o teste sem chance de escolha, o mesmo procedimento foi utilizado, com cada vaso coberto por gaiolas de tecido organza. Anteriormente à infestação, uma planta de cada vaso foi retirada, seca em estufa até peso constante para avaliação do teor de fenóis. Após 48 horas de infestação, os adultos liberados foram removidos das plantas para avaliação do número de ovos. Para isso, foi escolhida uma folha de uma planta/ vaso, selecionando-se a terceira folha apical inteiramente desenvolvida. Após quinze dias, foi avaliado o número de ninfas de $3^{\circ}$ e/ou $4^{\circ}$ ínstar. Não houve resposta entre cultivares de feijoeiro à aplicação de silício. Foi observado menor número de ovos e menor número de ninfas nas plantas tratadas com silício no teste com chance de escolha. No teste sem chance de escolha, a aplicação de silício não afetou a oviposição da mosca-branca e o desenvolvimento das ninfas, bem como o teor de fenóis.
\end{abstract}

Termos para indexação: Silício, mosca-branca, resistência induzida, MIP.

\begin{abstract}
The biotype B of Bemisia tabaci stands out among the main pests of the bean plant. The objective of this work was to evaluate the resistance induction to the whitefly by silicon application in bean plant. The experimental design was completely ranlomized with 4 treatments, in a 2 (cultivar Carioca and Brave) x 2 (with and without silicon application) factorial outline and 6 repiicates. Ten days after the emergence of the seedlings, $500 \mathrm{ml}$ of $1 \%$ silicic acid solution was applied in the soil, at a dosage equivalent to $2 \mathrm{t} \mathrm{SiO}_{2} / \mathrm{ha}$. Ten days after the silicon application, the plants were infested with non-sexed whitefly adults in an acclimatized room, wiht 100 whiteflys/vase. For the non-choice test, the same procedure was used, with each vase covered by cages of organza cloth. Previously to the infestation, a plant of each vase was removed, oven-dried to constant weight for the evaluation of phenol levels. After 48 hours of infestation, the liberated adults were removed from the plants for evaluation of the number of eggs. For that, a leaf of a plant/vase was chosen, selecting the third completely developed apical leaf. After fifteen days, the number of nymphs of 3rd and/or 4th instar were evaluated. There was no response among cultivars of common bean to silicon application. A lower number of eggs and lower number of nymphs were observed in the plants treated with silicon in the test with chance choice. In the no-choice test the silicon application did not affect the oviposition of the whitefly and the nymph development, as well as the phenol levels.
\end{abstract}

Index terms: Silicon, whitefly, induced resistance, IPM.

(Recebido em 1 de abril de 2010 e aprovado em 11 de novembro de 2010)

\section{INTRODUÇÃO}

O feijão tem grande importância econômica para o Brasil e, sua área plantada vem aumentando consideravelmente nos últimos anos. O plantio da primeira safra de 2009 foi confirmado em 1,44 milhão de hectares, representando um crescimento de 10,0\% em relação a 2007/08 (Companhia Nacional de Abastecimento - Conab, 2009).

Entre as principais pragas que ocorrem no feijoeiro, destaca-se a mosca-branca Bemisia tabaci biótipo B
(Barbosa et al., 1998) especialmente por ser vetor do "Bean golden mosaic vírus" (BGMV) causador do mosaico dourado do feijoeiro, doença que limita a produção de feijão em algumas áreas e é considerada, de acordo com Costa (1965), como a mais importante da cultura.

Uma estratégia de Manejo Integrado de Pragas (MIP) que oferece uma solução prática e de longa duração para a manutenção de baixas populações de mosca-branca é a resistência da planta hospedeira (Bellotti \& Arias, 2001). Dentro da resistência de plantas, a resistência induzida,

1 Universidade Estadual Paulista Júlio de Mesquita Filho - Departamento de Entomologia - Via de Acesso Professor Paulo Donato Castellane, s/n 14884-900 - Jaboticabal, SP - marilara19@yahoo.com.br

${ }^{2}$ Universidade Federal de Lavras/UFLA - Departamento de Entomologia/DEN - Lavras, MG 
que consiste no aumento do nível de resistência da planta por meio da utilização de agentes externos (indutores), sem qualquer alteração do genoma da planta é uma alternativa de controle de fácil manejo (Stadnik, 2000).

Um indutor de resistência bastante estudado é o silício, que quando é encontrado disponível em abundância na solução do solo pode conferir resistência ao ataque de insetos herbívoros e ao desenvolvimento e penetração de hifas dos fungos nos tecidos vegetais (Marschner, 1995). A proteção conferida às plantas pelo silício pode ser decorrente do seu acúmulo e polimerização de silicatados (sílica amorfa) nas células epidérmicas, logo abaixo da cutícula, formando uma barreira mecânica conhecida como "dupla camada silício-cutícula" que, pela diminuição da transpiração, faz com que a exigência de água pelas plantas seja menor (Korndörfer et al., 2004).

O silício, apesar de não ser considerado um elemento essencial, pode aumentar o rendimento de algumas espécies cultivadas, promovendo vários processos fisiológicos desejáveis para as plantas (Korndorfer \& Datnoff, 1995).

Desta forma, conduziu-se este trabalho, com o objetivo de avaliar o efeito da aplicação de ácido silícico na redução da preferência para oviposição de $B$. tabaci biótipo $\mathrm{B}$, o desenvolvimento de ninfas bem como avaliar o teor de fenóis em plantas de feijão.

\section{MATERIAL E MÉTODOS}

O experimento foi conduzido em casa de vegetação, em condições naturais, e no Laboratório de Resistência de Plantas a Insetos do Departamento de Entomologia da Universidade Federal de Lavras.

As moscas-brancas utilizadas foram coletadas da criação de manutenção, mantida em casa de vegetação em plantas de couve (Brassica oleracea L. var. acephala D.C.).

As cultivares de feijoeiro Valente e Carioca foram selecionadas de testes preliminares como moderadamente resistente e suscetível, respectivamente.

As sementes foram plantadas em vasos de polietileno com capacidade para $5 \mathrm{~kg}$ de solo, preenchidos com mistura de terra e composto orgânico, na proporção de 3:1. Foram semeados seis sementes por vaso, sendo 24 vasos para cada cultivar de feijão, mantendo-se duas ou quatro plantas após o desbaste, de acordo com o teste a ser realizado. As plantas foram irrigadas diariamente, de modo a suprir suas necessidades hídricas.

Dez dias após a emergência das plantas, foi aplicado no solo ao redor das plântulas $500 \mathrm{ml}$ de solução de ácido silícico a $1 \%$, equivalente a $2 \mathrm{t} \mathrm{SiO}_{2} / \mathrm{ha}$, em 12 vasos de cada cultivar. Nos outros 12 vasos, foram aplicados $500 \mathrm{ml}$ de água como controle. Foram testados os seguintes tratamentos: T1 - cultivar Valente; T2 - cultivar Valente com aplicação de silício; T3 - cultivar Carioca e T4 cultivar carioca com aplicação de silício.

\section{Teste com chance de escolha}

Vinte dias após a emergência das plântulas, 24 vasos com duas plantas/vaso (seis vasos por tratamento) foram dispostos ao acaso em bancada da sala climatizada do Laboratório de Resistência de Plantas a Insetos.

Para a infestação foram coletados da criação de manutenção, com auxílio de aspirador manual, 100 adultos não sexados de mosca-branca/vaso, colocados em tubos, e liberados em sala climatizada de $3 \mathrm{~m}$ de comprimento, $2 \mathrm{~m}$ de largura e $1,8 \mathrm{~m}$ de altura, sendo um tubo por vaso colocado sobre o substrato. Totalizando 2.400 indivíduos para esse teste.

Após 48 horas de infestação, os adultos liberados foram removidos das plantas para avaliação do número de ovos. Para isso, foi escolhida uma folha de uma planta/vaso, selecionando-se a terceira folha apical inteiramente desenvolvida (Moraes et al., 2009). No laboratório, com o auxílio de microscópio estereoscópico, foi contado o número de ovos na face abaxial de cada folíolo da folha selecionada.

Quinze dias após a retirada dos adultos que haviam sido liberados, foi feita a avaliação do número de ninfas de terceiro e/ou quarto ínstar, na terceira folha apical totalmente desenvolvida da outra planta de cada vaso. Essas folhas foram retiradas das plantas, acondicionadas em sacos de papel e levadas para o laboratório, onde foram examinadas com o auxílio de microscópio estereoscópico, para contagem do número de ninfas.

\section{Teste sem chance de escolha}

Adotaram-se os mesmos procedimentos empregados no teste anterior, sendo que, neste teste, foram cultivadas quatro plantas por vaso e, posteriormente, retiradas duas plantas, antes da infestação com as moscasbrancas, para a posterior determinação do teor de fenóis. Os vasos foram individualizados em gaiolas de $25 \mathrm{~cm}$ de diâmetro e $50 \mathrm{~cm}$ de altura, construídas com hastes de madeira nas laterais e cobertas com tecido organza (Moraes et al., 2009) e dispostas aleatoriamente em bancada em casa de vegetação.

O número de ovos e de ninfas de terceiro e/ou quarto ínstar foram avaliados, da mesma maneira que no teste com chance de escolha.

\section{Determinação de fenóis}

As duas plantas retiradas de cada vaso antes da infestação no teste sem chance de escolha, após secagem 
em estufa a $60^{\circ} \mathrm{C}$, tiveram suas folhas retiradas e trituradas em micro moinho do tipo Willy TE-648, peneira de 30 "mesh", sendo as amostras enviadas ao Laboratório de Produtos Vegetais do Departamento de Ciência dos Alimentos - UFLA, para análise de fenóis.

\section{Análise dos dados}

O delineamento experimental utilizado foi o inteiramente casualizado, com seis repetições, em esquema fatorial $2 \times 2$, sendo dois níveis de silício (com e sem aplicação de silício) e duas cultivares de feijão (Valente e Carioca). Os dados foram submetidos à análise de variância $(p \leq 0,05)$, sendo os de contagem transformados em $(x+0,5)^{1 / 2}$ antes da análise. As médias foram comparadas diretamente no quadro de análise de variância.

\section{RESULTADOS E DISCUSSÃO}

No teste com chance de escolha não foi verificado efeito isolado de cultivar, ou mesmo a interação entre cultivar e silício. Contudo, à aplicação de silício, na média das cultivares Carioca e Valente, proporcionou redução na oviposição e no desenvolvimento das ninfas de $B$. tabaci biótipo $\mathrm{B}$ (Tabela 1). A redução no número de ovos nas plantas tratadas com silício em relação às não tratadas, aproximadamente 1,9 vezes, pode estar associada ao comportamento do inseto em preferir ovipositar em plantas que garantam o desenvolvimento e a sobrevivência de suas ninfas. Já, o menor número de ninfas, de 2,7 vezes menor nas plantas tratadas com silício em relação às não tratadas, pode estar relacionado a uma possível indução nas plantas de algum composto secundário de defesa pela aplicação de silício.

Entretanto, não se observaram efeitos isolados ou a interação dos fatores cultivares e aplicação de silício no teste sem chance de escolha, sendo as médias de oviposição e de número de ninfas de $B$. tabaci não significativas (Tabela 2). Pode-se também observar (Tabela 2) que as médias do teor de fenóis não foram significativas para a aplicação de silício.
Tabela 1 - Número de ovos e de ninfas/folha $(\mathrm{m} \pm \mathrm{EP}) \mathrm{de}$ Bemisia tabaci Biótipo B em teste com chance de escolha em feijoeiro tratado e não tratado com silício. T diurna: $28^{\circ} \mathrm{C}$ $\pm 2^{\circ} \mathrm{C}$, T noturna: $25^{\circ} \mathrm{C} \pm 2^{\circ} \mathrm{C}$, UR $70 \pm 10 \%$.

\begin{tabular}{lcc}
\hline Tratamento & Número de ovos* & Número de ninfas* \\
\hline Sem silício & $73,7 \pm 14,26 \mathrm{a}$ & $28,3 \pm 3,86 \mathrm{a}$ \\
Com silício & $39,0 \pm 14,0 \mathrm{~b}$ & $10,4 \pm 3,09 \mathrm{~b}$ \\
\hline $\mathrm{CV}(\%)$ & 44,02 & 35,37 \\
\hline
\end{tabular}

*Médias com letras diferentes na coluna diferem estatisticamente entre si pelo teste $\mathrm{F}(p \leq 0,5)$.

Como nesta pesquisa, efeitos negativos da aplicação de silício na oviposição de $B$. tabaci biótipo B também foram verificados em feijoeiro (Almeida et al., 2008) e em plantas de pepino (Correa et al., 2005), em teste com chance de escolha. Contudo, em soja, pertencente à mesma família do feijoeiro, a aplicação de silício não afetou a preferência para oviposição da mosca-branca, porém causou maior mortalidade de ninfas (Moraes et al., 2009).

Em teste sem chance de escolha, de forma similar a essa pesquisa, a oviposição de $B$. tabaci biótipo B não diferiu significativamente entre as plantas de pepino tratadas e não tratadas com silício (Correa et al., 2005).

A ausência de resposta do silício para o teor de fenóis pode estar relacionada ao intervalo e/ou número de aplicações do indutor que, segundo Paschoalati \& Leite (1995), pode ser necessária mais de uma aplicação para a síntese e acúmulo de substâncias que conferem resistência às plantas. Em soja, por exemplo, a aplicação de silício induziu aumento no teor de lignina na cultivar de soja IAC19 (Moraes et al., 2009).

De uma maneira geral, os resultados obtidos foram consistentes apenas para a não-preferência de oviposição e para o desenvolvimento de ninfas, quando a mosca-branca teve chance de escolha entre os diferentes hospedeiros. Portanto, ainda serão necessários outros experimentos, principalmente a campo, para aferição dessa tática de manejo de B. tabaci biótipo B em cultura de feijoeiro.

Tabela 2 - Número de ovos, de ninfas/folha $(\mathrm{m} \pm \mathrm{EP})$ de Bemisia tabaci Biótipo B e teor de fenóis em teste sem chance de escolha em feijoeiro tratado e não tratado com silício. T $27^{\circ} \mathrm{C} \pm 2^{\circ} \mathrm{C}$, UR $60 \pm 10 \%$.

\begin{tabular}{lccc}
\hline Tratamento & Número de ovos* & Número de ninfas* & Fenóis $(\mathrm{mg} / 100 \mathrm{~g})^{*}$ \\
\hline Sem silício & $13,7 \pm 2,79$ & $4,7 \pm 1,27$ & $14,2 \pm 0,89$ \\
Com silício & $10,1 \pm 2,83$ & $6,7 \pm 2,99$ & $14,5 \pm 0,84$ \\
\hline $\mathrm{CV}(\%)$ & 45,42 & 59,65 & 21,58 \\
\hline *Médias com diferenças não significativas pelo teste $\mathrm{F}(p<0,5)$. &
\end{tabular}




\section{CONCLUSÕES}

Não houve resposta entre cultivares de feijoeiro à aplicação de silício.

O silício aplicado em plantas de feijão induz a nãopreferência para oviposição e afeta o desenvolvimento de ninfas de B. tabaci biótipo B, em teste com chance de escolha.

Em teste sem chance de escolha, o silício não afeta a oviposição e o desenvolvimento de ninfas de $B$. tabaci biótipo B em plantas de feijão.

A aplicação de silício na cultura do feijoeiro não afeta o teor de fenóis totais para as condições do trabalho.

\section{AGRADECIMENTOS}

Ao Conselho Nacional de Desenvolvimento Científico e Tecnológico - CNPq pelo apoio ao projeto.

\section{REFERÊNCIAS BIBLIOGRÁFICAS}

ALMEIDA, G.D.; PRATISSOLI, D.; HOLTZ, A.M.; VICENTINI, V.B. Fertilizante organomineral como indutor de resistência contra a colonização da mosca branca no feijoeiro. IDESIA, Chile, v.26, n.1, p.29-32, 2008.

BARBOSA, F.B.; YOKOYAMA, M.; SILVA, P.H.S. da; BLEICHER, E.; HAN, F.N.P.; ALENCAR, J.A. de; CARNEIRO, J. da S.; ARAÚJO, L.H.A. de. Proposta de manejo da mosca-branca Bemisia argentifolii Bellows \& Perring no feijão Phaseolus vulgaris L. In: EMPRESA BRASILEIRA DE PESQUISA AGROPECUÁRIA. Manejo integrado da mosca-branca: plano emergencial para o controle da mosca-branca. São Paulo, 1998.

BELLOTTI, A.C.; ARIAS, B. Host plant resistance to whiteflies with emphasis on cassava as a case study. Crop Protection, Guildford, v.20, n.9, p.813-823, Nov. 2001.

COMPANHIA NACIONAL DE ABASTECIMENTO. Brasília: Ministério da Agricultura, Pecuária e do Desenvolvimento, 2009. Disponível em: <http://
'Www.conab.gov.br/conabweb/download $x$. Acesso em: 12 ago. 2009 .

CORREA, R.S.B.; MORAES, J.C.; AUAD, A.M.; CARVALHO, G.A. Silicon and acibenzolar-S-methyl as resistance inducers in cucumber, against the whitefly Bemisia tabaci (Gennadius) (Hemiptera: Aleyrodidae) biotype B. Neotropical Entomology, Londrina, v.34, n.3, p.429-433, July/Sept. 2005.

COSTA, A.S. Three whitefly-transmitted vírus diseases of beans in São Paulo, Brazil. FAO Plant Protection Bulletin, Rome, v.13, n.1, p.121-130, Jan./Mar. 1965.

KORNDÖRFER, G.A.; DATNOFF, L.E. Adubação com silício: uma alternativa no controle de doenças de canade-açúcar e do arroz. Informações Agronômicas, Piracicaba, n.70, p.1-5, jun. 1995.

KORNDÖRFER, G.H.; PEREIRA, H.S.; CAMARGO, M.S. Silicatos de cálcio e magnésio na agricultura. 3.ed. Uberlândia: GPSi, 2004. 23p.

MARSCHNER, H. Mineral nutrition of higher plants. 2.ed. London: Academic, 1995. 889p.

MORAES, J.C.; FERREIRA, R.S.; COSTA, R.R. Indutores de resistência à mosca-branca Bemisia tabaci biótipo $\mathrm{B}$ (Genn., 1889) (Hemiptera: Aleyrodidae) em soja. Ciência e Agrotecnologia, Lavras, v.33, n.5, p.1260-1264, set./out. 2009.

PASCHOALATI, S.F.; LEITE, B. Hospedeiro: mecanismo de resistência. In: BERGAMIN FILHO, A.; KIMATI, H.; AMORIM, L. (Eds.). Manual de fitopatologia: princípios e conceitos. São Paulo: Agronômica Ceres, 1995. v.1, cap.22, p.417-454.

STADNIK, M. Indução de resistência a oídios. In: CONGRESSO PAULISTA DE FITOPATOLOGIA, 23., 2000, Campinas. Anais... Campinas: GPF, 2000. p.176-181. 